\title{
DISTRIBUIÇÃO ESPACIAL DE EQUIPAMENTOS DE MAMOGRAFIA NO BRASIL
}

\section{SPATIAL DISTRIBUTION OF MAMMOGRAPHY EQUIPMENT IN BRAZIL}

\author{
Pedro Amaral A, B, C, E, F \\ LuCiana Luz A, E, F \\ Universidade Federal de Minas Gerais, Centro de Desenvolvimento e Planejamento Regional, Belo Horizonte, MG, Brasil \\ Francisco Cardoso A, E, F \\ Rosiene Freitas A, E, F \\ Universidade Federal de Minas Gerais, Núcleo de Educação em Saúde Coletiva, Belo Horizonte, MG, Brasil
}

R E S U M O : Este trabalho avalia a rede de oferta de mamógrafos no Brasil a partir da disponibilidade regional do equipamento e da distância entre demanda potencial e oferta de equipamentos no âmbito municipal. Os resultados demonstram que a quantidade total de mamógrafos no Brasil seria suficiente para o atendimento da população, dada a previsão de necessidade estipulada pela nota técnica do Instituto Nacional do Câncer (INCA). Todavia, quando se limita o alcance da oferta a uma distância de $60 \mathrm{~km}$, é possível identificar regiôes em que não há provisão do equipamento e, ao mesmo tempo, áreas que concentram uma quantidade de equipamento superior à necessária, o que indica uma desigualdade locacional na distribuição espacial de mamógrafos.

P A L A V R A S - C H A V E : distribuição espacial; saúde; mamógrafos.

A B S T R A C T : This study evaluates the mammography equipment supply network in Brazil, considering the regional availability of the equipment and the distance between potential demand and supply of equipment at the municipal level. The results show that the total number of mammography equipment in Brazil should be enough to attend the population, considering the estimated demand according to a technical note from the National Institute of Cancer (INCA). However, when the distance range of supply is limited to $60 \mathrm{~km}$, it is possible to identify regions where there is no equipment provision, while other regions concentrate more equipment than necessary, indicating locational inequality in the spatial distribution of mammography equipment.

K E Y W O R D S : spatial distribution; health; mammography equipment. 


\section{INTRODUÇÃO}

Como estabelecido na Constituição Brasileira de 1988, o Sistema Único de Saúde (SUS) tem a responsabilidade de garantir acesso a serviços de saúde a todos os cidadãos brasileiros, com ampla cobertura de suas necessidades e tratamento igualitário a pessoas com necessidades iguais, isto é, tratamento com equidade horizontal. Um dos requisitos para a equidade horizontal é o acesso balanceado aos centros de saúde para recebimento de diagnóstico ou realização de tratamento. Acesso balanceado implica possibilidade de acesso igualitário a pessoas com necessidades iguais. Portanto, o conceito de acessibilidade abrange mais que a simples existência ou disponibilidade de recursos em dado período de tempo (ADAY; ANDERSEN, 1974); na verdade, ele está também ligado à capacidade de os indivíduos se apropriarem dos serviços oferecidos.

Diversos fatores podem dificultar ou criar obstáculos ao acesso a serviços de saúde, como disponibilidade de convênios ou seguros, diferenças culturais, nível educacional (incluindo conhecimento de condiçôes de saúde e tratamentos), status socioeconômico, custos de transporte, localização dos centros de saúde, entre outros. Esses fatores podem ser classificados em duas categorias principais: fatores sócio-organizacionais e acessibilidade geográfica (DONABEDIAN, 1973).

Sob a ótica da acessibilidade geográfica, a provisão espacial (ou configuração geográfica da rede de oferta) de serviços de saúde exerce, juntamente com o sistema de transporte, um papel fundamental. Como afirma Whitehead (1992), a equidade no cuidado da saúde baseia-se no princípio de tornar a oferta de serviços de qualidade acessível a todos. Não basta ser oferecido o serviço de saúde, é necessário, igualmente, que o paciente seja capaz de alcançar o centro onde ele é ofertado em tempo e custos razoáveis (HAMER, 2004), ou seja, há que se considerar uma rede de provisão geograficamente balanceada. A configuração dessa rede requer uma avaliação da "fricção espacial" no acesso aos serviços em conjunto com uma análise da distribuição espacial dos centros de saúde, dos recursos e profissionais, vis-à-vis à distribuição da população (JOSEPH; BANTOCK, 1982; KHAN, 1992).

A oferta de serviços de saúde de média e alta complexidade se beneficia da concentração espacial, devido aos retornos crescentes de escala associados à provisão deles (IUNES, 1995; POL; THOMAS, 2000). Essa característica, aliada ao fato de os profissionais de saúde geralmente preferirem habitar em centros urbanos e áreas mais desenvolvidas (KUHN; OCHSEN, 2009; PÓVOA; ANDRADE; MORO, 2004), resulta na tendência de concentraçáo de serviços de saúde ao redor de aglomerados urbanos e em sua consequente escassez em áreas relativamente menos desenvolvidas e rurais. Uma vez que a condição de saúde se associa ao status socioeconômico (NORONHA, 2001) e que a estrutura espacial da oferta de serviços de saúde impacta suas taxas de utilização (HIGGS, 2009), tal concentração é perversa, no sentido de que a provisão é escassa nos locais em que ela talvez seja mais necessária: a chamada “inverse care law" (HART, 1971).

Poucos trabalhos abordam explicitamente o papel da distância geográfica na provisão de serviços de saúde no Brasil, e grande parte dos que o fazem limita-se à análise de apenas um Estado ou região. Neste estudo, é considerada espacialmente a oferta de equipamentos de mamografia em todos os municípios brasileiros. Para 
tanto, analisa-se a quantidade de equipamentos de mamografia privados e públicos em uso, além dos mamógrafos disponíveis para o SUS em dezembro de 2015.

No âmbito nacional, encontra-se em uso, no Brasil, uma quantidade de mamógrafos suficiente para o completo atendimento da população, tendo em vista os parâmetros propostos para disponibilização desses equipamentos pelo Ministério da Saúde (BRASIL, 2015). A quantidade de mamógrafos em uso em dezembro de 2015 era de 4.647 máquinas. Destas, 2.083 estavam disponíveis para o SUS, o que seria mais do que suficiente para atender à demanda estimada de 12,7 milhóes de exames por ano. De fato, 1.875 mamógrafos já seria um número suficiente para atendimento da demanda estimada.

Apesar da existência de um número satisfatório de mamógrafos, esses equipamentos encontram-se mal distribuídos pelo país, conforme será discutido ao longo deste estudo. Quando se impóe um limite máximo de distância de cobertura e a capacidade de cada equipamento é observada, nota-se, por um lado, que a população de diversos municípios se encontra completamente sem cobertura e, por outro, que alguns municípios apresentam uma quantidade excessiva do equipamento. Segundo o Ministério da Saúde (BRASIL, 2015), "para a alocação dos equipamentos [de mamografia][,] deve-se considerar o acesso das usuárias ao exame. Para essa garantia [,] propóe-se o parâmetro de tempo de deslocamento de 60 minutos, ou a distância máxima de 60 quilômetros". Ao definir o limite máximo de $60 \mathrm{~km}$ de distância entre o município de residência e o município de localização do mamógrafo em uso mais próximo, 4,5\% de todos os exames necessários no Brasil não poderiam ser realizados, o que representa mais de 572 mil exames. Todavia, se se considera apenas os equipamentos disponíveis para o SUS, $17 \%$ dos exames esperados não seriam realizados por falta de mamógrafos num raio de $60 \mathrm{~km}$ do município de residência da paciente, isto é, mais de 2,17 milhôes de exames.

Com recursos limitados, e uma vez que o acesso aos serviços de saúde depende, ao mesmo tempo, da disponibilidade e do alcance, a localização ineficiente de equipamentos de saúde é não somente um desperdício de recursos, mas também um sério problema social. Nesse sentido, a análise da distribuição espacial dos mamógrafos no território brasileiro é relevante para a avaliação da equidade da disponibilização do equipamento e para a identificação das áreas mais carentes de investimentos, aspectos que devem ser observados com vistas a reduzir a desigualdade regional de acesso a serviços de saúde no Brasil.

\section{A DISTRIBUIÇÃO ESPACIAL DE SERVIÇOS DE SAÚDE NO BRASIL}

Distância e padrôes espaciais têm ganhado importância nos estudos sobre saúde desde o trabalho de John Snow acerca da epidemia de cólera em Londres em 1845. Essa evoluçáo levou ao reconhecimento da área, que, posteriormente, foi chamada de "geografia da saúde" (KEARNS; MOON, 2002). O foco desses trabalhos pode ser dividido em dois grupos gerais: epidemiologia geográfica e planejamento de sistemas de saúde (MAYER, 1982). Em relação ao planejamento de sistemas de saúde, a análise espacial e os Sistemas de Informação Georreferenciados (SIG) são de grande utilidade na alocação e planejamento de serviços de saúde (SUI, 2007). Estudos que trazem 
uma revisão da literatura contemplam a evolução da pesquisa no campo da geografia da saúde e suas diferentes aplicaçóes em vários países (BROWN; DUNCAN, 2002; ANDREWS; MOON, 2005; HIGGS, 2004; SUI, 2007). Eles mostram que a análise espacial tem sido amplamente usada para explorar a relação entre acesso geográfico, utilização, qualidade e indicadores de saúde.

No Brasil, o tema da distribuição espacial de serviços de saúde atraiu a atenção de muitos pesquisadores, sendo abordado em diversos trabalhos, como Gasparini e Ramos (2004), Oliveira, Carvalho e Travassos (2004), Simóes et al. (2005), Botega, Rodrigues e Andrade (2006), entre outros. Gasparini e Ramos (2004) desenvolveram um índice de déficit relativo para os estados brasileiros usando o Data Envelopment Analysis. Os resultados por eles obtidos revelaram que Estados na região Sul são os que estão mais próximos da fronteira de eficiência, enquanto os da região Nordeste são os que se encontram mais distantes. Entretanto, o índice de déficit proposto pelos autores possui limitaçôes, pois agrega serviços hospitalares heterogêneos quanto ao nível de complexidade e não apresenta uma medida absoluta para o déficit. Além disso, ele considera uma escala geográfica muito abrangente, escondendo, assim, a vasta heterogeneidade interna existente nos Estados.

Utilizando dados dos municípios, Oliveira, Carvalho e Travassos (2004) mapeiam uma rede de provisão dos serviços de saúde baseada na origem e destino dos pacientes. Os resultados apresentam, por um lado, uma extensa rede de provisão de serviços de saúde básica, na qual somente alguns poucos municípios estão desconectados. Por outro lado, de acordo com o trabalho, quase metade dos municípios brasileiros estariam desconectados de uma rede de provisáo de serviços de alta complexidade. Contudo, o artigo de Oliveira, Carvalho e Travassos (2004) não leva em consideração medidas de distância ou fricção espacial. Segundo a análise apresentada pelos autores, mesmo que aproximadamente $20 \%$ dos pacientes tenham de viajar mais de 60 quilômetros para acessar serviços hospitalares comuns, a distância não desempenha um papel significativo nos resultados encontrados. Ademais, não são levadas em conta a demanda e a oferta dos serviços de saúde, mas somente a quantidade de serviços que de fato é provida em dado período. Um estudo semelhante foi feito por Oliveira, Simóes e Andrade (2008) para o Estado de Minas Gerais, no qual se avalia a rede de provisão de serviços alta complexidade.

Simóes et al. (2005) também examinam os desequilíbrios regionais na oferta de serviços de saúde em Minas Gerais. Os autores encontraram dois padróes espaciais distintos no Estado, um no Norte e outro no Sul, evidenciando as disparidades regionais. Já para o norte do Brasil, na região amazônica, os resultados apresentados em Simôes, Rodrigues e Amaral (2008) sugerem uma forte concentração da oferta nas principais capitais da região e identificam importantes lacunas, inclusive na provisão de serviços básicos de saúde. Por sua vez, Rodrigues, Amaral e Simóes (2007), em uma análise de todas as macrorregiōes brasileiras, mostram que a oferta de serviços de saúde concentra-se principalmente no Sul e Sudeste do país. No entanto, os trabalhos citados se limitam a uma análise da oferta de serviços de saúde, sem uma avaliação da distribuição espacial da demanda.

Especificamente em relação à distribuição de mamógrafos, merece destaque o estudo de Villar et al. (2015), que descreve, em detalhes, a distribuição dos mamógrafos e das mamografias realizadas no Estado do Rio de Janeiro. Tomando como base os parâmetros de ofertas propostos pela Portaria 1.101 do Ministério da Saúde 
(BRASIL, 2002), as autoras identificam desigualdades na distribuição espacial dos equipamentos, concluindo, porém, que, no período estudado, não havia déficit de mamógrafos em comparação com o parâmetro nacional. Elas indicam ainda uma ociosidade na utilização dos equipamentos.

Em comum, esses trabalhos desconsideram a distância ou a fricção espacial, ao menos explicitamente, no mapeamento da rede de provisão ou da distribuição espacial da oferta de serviços de saúde. Entre os poucos estudos que tratam de forma explícita do papel exercido pela distância geográfica na provisão de serviços de saúde, devem ser ressaltados os de Oliveira, Travassos e Carvalho (2004), Oliveira (2004) e Botega, Rodrigues e Andrade (2006). Oliveira, Travassos e Carvalho (2004) demonstram como a probabilidade de ser internado na rede SUS no Brasil aumenta com a disponibilidade local de atendimento básico e leitos hospitalares. De acordo com os resultados do mesmo estudo, a probabilidade de internaçáo é menor em municípios maiores ou mais ricos. A probabilidade de ser internado na rede SUS também cai com o aumento da distância entre o centro de provisão do serviço hospitalar e o município de origem do paciente. Já Oliveira (2004) e Botega, Rodrigues e Andrade (2006) analisam os serviços hospitalares somente no Estado de Minas Gerais. Ambas as pesquisas salientam a existência de uma relação negativa entre distância e internaçôes, bem como pontuam que serviços de alta complexidade tendem a ser espacialmente concentrados.

\section{DADOS E ANÁLISE EXPLORATÓRIA}

Este estudo examina a distribuição espacial de mamógrafos nos municípios brasileiros. Para tanto, são utilizados os dados do Cadastro Nacional de Estabelecimentos de Saúde (CNES-DATASUS) sobre a quantidade e localização do total de mamógrafos em uso e também daqueles disponíveis para o SUS em dezembro de 2012. Cabe ressaltar que os equipamentos oferecidos pela rede privada não necessariamente se encontram disponíveis na rede pública, podendo ter, portanto, sua oferta restrita; esse aspecto póe em relevo a possibilidade de superestimaçáo da oferta de equipamentos nas localidades em que existe forte presença do setor privado na prestação de serviços de saúde, quando a variável de interesse é a oferta total de equipamentos em uso. Por sua vez, como nem toda a populaçáo busca acesso a equipamentos disponíveis pelo SUS, basear a análise apenas nesses equipamentos implica a possibilidade de superestimação da demanda. Ao avaliar os dois cenários extremos, busca-se contornar esses problemas.

A Tabela 1 apresenta os dados da quantidade de municípios que possuem mamó-

1 Segundo o IBGE, em 2015 o Brasil contava com 5.570 municípios. Todavia, neste trabalho, os municípios Mojuí dos Campos, Pescaria Brava, Balneário Rincão, Pinto Bandeira e Paraíso das Águas foram reincorporados àqueles que mais cederam área para sua criação. grafos em uso e mamógrafos disponíveis pelo SUS no Brasil. Dos $5.565^{1}$ municípios brasileiros, $1.079(19,4 \%)$ possuem ao menos um mamógrafo em uso e $950(17,1 \%)$ têm mamógrafo disponível para o SUS. Entre os municípios que possuem o equipamento, o número médio de mamógrafos é de 4,31 equipamentos em uso e 2,19 disponíveis para o SUS, respectivamente. 
Tabela 1: Quantidade de municípios que possuem mamógrafos em uso e disponibilizados pelo SUS no Brasil

\begin{tabular}{lccccc}
\hline & Obs. & Média & Desvio-padrão & Min. & Max \\
\hline $\begin{array}{l}\text { Número de municípios que possuem } \\
\text { mamógrafos em uso }\end{array}$ & 1079 & 4,31 & 14,37 & 1 & 346 \\
\hline $\begin{array}{l}\text { Número de municípios que possuem } \\
\text { mamógrafos disponíveis para o SUS }\end{array}$ & 950 & 2,19 & 3,34 & 1 & 62 \\
\hline $\begin{array}{l}\text { Número de mamógrafos em uso por } \\
1.000 \text { habitantes }\end{array}$ & 1079 & 0,05 & 0,04 & 0,003 & 0,40 \\
\hline $\begin{array}{l}\text { Número de mamógrafos disponíveis } \\
\text { para o SUS por 1.000 habitantes }\end{array}$ & 950 & 0,04 & 0,04 & 0,002 & 0,40 \\
\hline
\end{tabular}

Fonte: CNES/DATASUS - Dez/2015; Estimativa de população 2015, IBGE.

Dos 4.647 mamógrafos em uso distribuídos no território nacional em 2015, 11,5\% concentravam-se nas cidades de Sáo Paulo e Rio de Janeiro - um total de 536 unidades. Já a concentração de equipamentos disponíveis para o SUS era significativamente menor: Sáo Paulo e Belo Horizonte, as duas cidades com maior concentração, respondiam por 94 das 2.083 máquinas, o equivalente a 4,5\%. O número de mamógrafos por mil habitantes, em cidades que possuem o equipamento, é em média de 0,05 unidades em uso e 0,04 disponíveis para o SUS, o que equivale a 1 mamógrafo em uso por 20.000 habitantes, e a 1 por 25.000 no SUS.

Figura 1: Distribuição espacial da população no Brasil

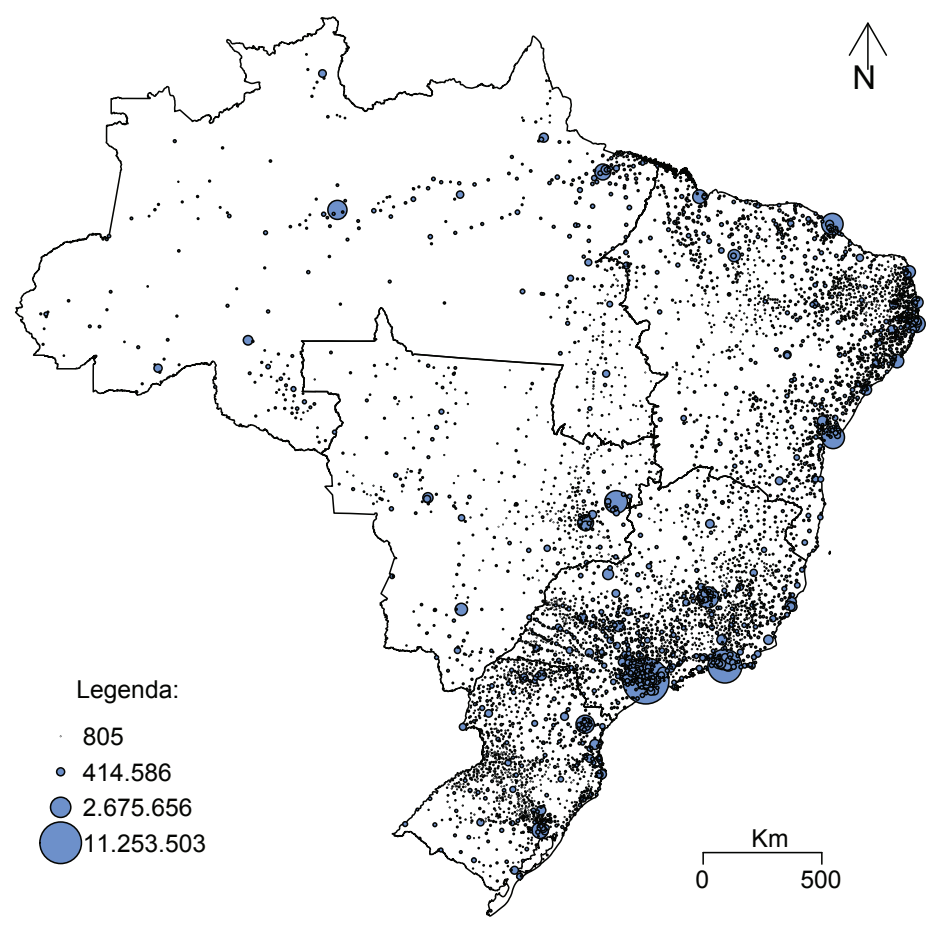

Fonte: Elaborado pelos autores. 
Figura 2: Distribuição espacial de mamógrafos em uso (a) e disponíveis para o SUS (b) por mil habitantes no Brasil

(a)

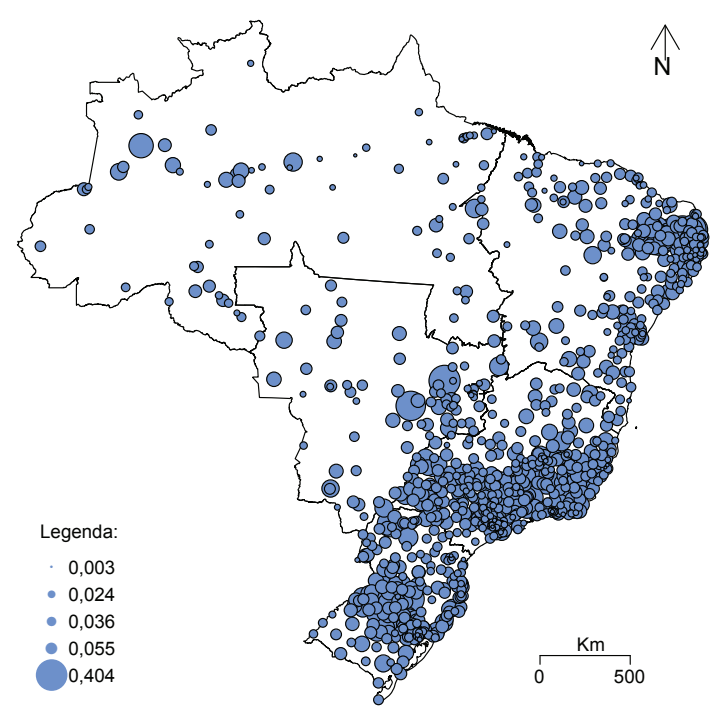

(b)

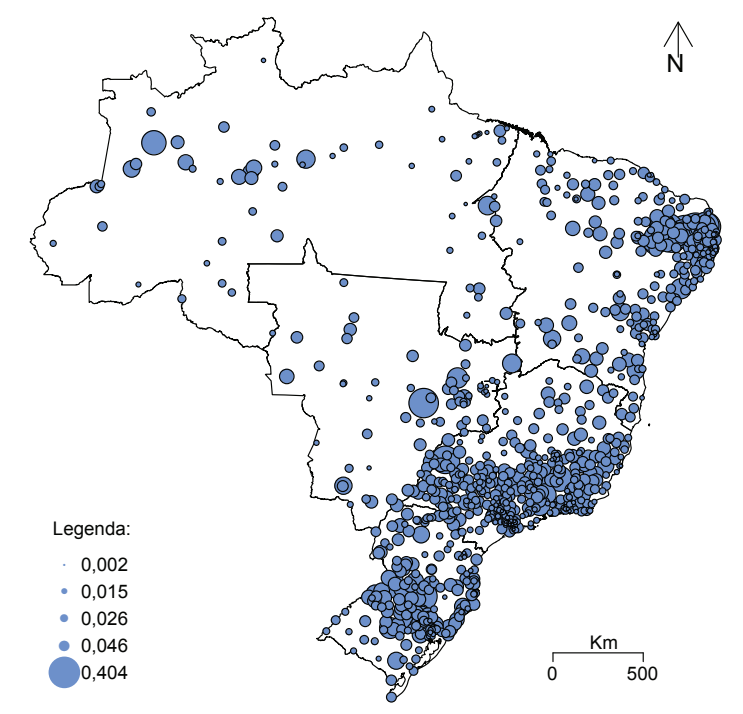

Fonte: Elaborado pelos autores.

A Figura 2 apresenta a distribuição espacial de mamógrafos por mil habitantes no Brasil. Quando comparada à distribuição espacial da população (Figura 1), observase a presença de vazios na provisão do equipamento nas regiōes Norte, Centro-Oeste e Nordeste, bem como no norte de Minas Gerais, indicando uma inadequação entre oferta e demanda na distribuição espacial de mamógrafos, principalmente quando são analisados apenas os equipamentos disponíveis para o SUS, que possui uma rede de oferta ainda menos densa. Essa inadequação é ainda mais notória quando a análise limita o acesso a mamógrafos a uma distância máxima, como será discutido a seguir.

\section{METODOLOGIA}

Como descrito anteriormente, este estudo se baseia nos critérios e parâmetros para o planejamento e programação de açóes e serviços de saúde do SUS (BRASIL, 2015). Em relação à provisão de mamógrafos, esses critérios acompanham a nota técnica do Instituto Nacional de Câncer (INCA) de 23 de fevereiro de 2012 (INCA, 2012), que estabelece a produção de 6.758 mamografias por equipamento por ano, considerando a realização de 32 exames diários e uma capacidade de produçáo de $80 \%$. Com base no número de mamógrafos existentes em cada município brasileiro, é possível calcular quantos exames os municípios poderiam potencialmente realizar, isto é, a oferta potencial. Por exemplo, um município com quatro mamógrafos possuiria uma oferta potencial suficiente para realizar 27.032 exames.

Para calcular a demanda estimada, deve-se recorrer, mais uma vez, aos parâmetros do INCA (2009) e à projeção de demanda adotada pelo Ministério da Saúde (BRASIL, 2015). Tais documentos apontam para a necessidade de realização de exames anuais em 
$20 \%$ das mulheres de 40 a 49 anos, sendo $10 \%$ por indicação diagnóstica e $10 \%$ por outras indicaçóes. Para todas as mulheres de 50 a 69 anos, propóe-se a realização de exames bianuais de rastreamento, além de um adicional de $8,9 \%$ anual por indicação diagnóstica para mulheres nessa faixa etária. Ou seja, para mulheres de 50 a 69 anos, a demanda estimada é de $58,9 \%$ da população feminina por ano ${ }^{2}$.

Voltando ao exemplo de um município com quatro mamógrafos (capaz de realizar 27.032 exames), se se parte da hipótese de uma demanda estimada de 25.000 exames, o excesso de oferta seria suficiente para realizar mais 2.032 exames (27032 $25000=2032$ ) na população de municípios próximos.

Apesar da importância do acesso ao equipamento de saúde, há que se levar em conta, ainda, as distâncias máximas, as quais os pacientes deverão se dispor a percorrer para que recebam atendimento. Como visto na introdução, segundo indicação do Ministério da Saúde (BRASIL, 2015, p. 93), "para a alocação dos equipamentos [,] deve-se considerar o acesso das usuárias ao exame. Para essa garantia [,] propóe-se o parâmetro de tempo de deslocamento de 60 minutos, ou a distância máxima de 60 quilômetros". Portanto, aqui, o alcance, ou área de cobertura, de uma unidade de saúde com oferta de mamógrafo é restringido a um raio de $60 \mathrm{~km}$ ou limitado por capacidade de atendimento, caso esta se esgote antes mesmo de atingir a distância máxima estabelecida. Esse alcance representa a distância máxima em que o excesso de oferta de um centro regional de saúde pode ser utilizado para atender ao déficit de demanda das localidades vizinhas. Um exemplo é apresentado na Figura 3.

Figura 3: Alcance potencial em uma rede de atendimento

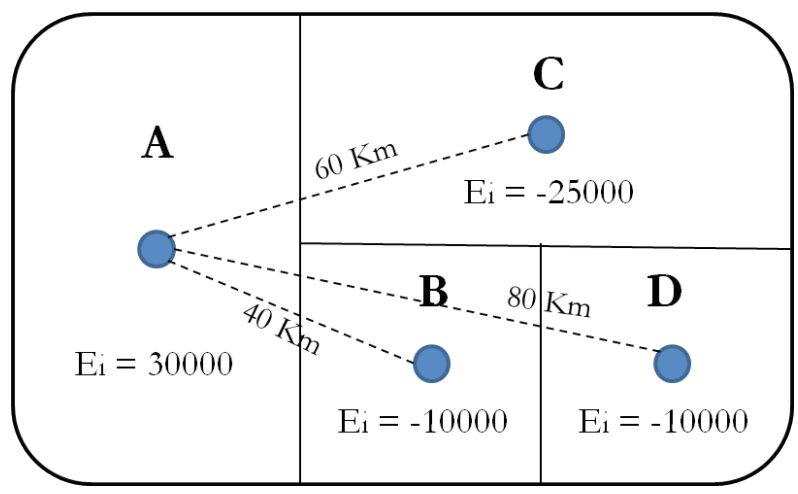

Fonte: Elaborado pelos autores.

Nesse exemplo, a unidade de saúde A é a única localidade na regiáo que possui excesso de oferta de equipamento. $\mathrm{O}$ excesso de oferta em $\mathrm{A}$ é de $E_{A}=30.000$, ou seja, suficiente para realização de 30 mil exames, enquanto as localidades B, C e D apresentam déficits, respectivamente, de $E_{B}=-10.000, E_{C}=-25.000$ e $E_{D}=-10.000$. A distância entre o centro de saúde A e cada uma das demais localidades também é salientada na Figura 3. Percebe-se que a localidade B é a vizinha mais próxima de A. Dados os excessos de oferta e demanda de ambas, os exames demandados pela população de $\mathrm{B}$ podem ser realizados pelas unidades de saúde de $\mathrm{A}$. Se todos os exames de $\mathrm{B}$ forem feitos em $\mathrm{A}$, o excesso de oferta de A seria reduzido para $E_{A+B}=20.000$.

$\mathrm{O}$ seguinte vizinho mais próximo de $\mathrm{A}$ é a localidade $\mathrm{C}$. Contudo, o excesso de demanda em C (25.000) é superior ao excesso de oferta em A - líquido do atendimento
2 A estimativa municipal do número de mulheres por faixa etária foi realizada tomando como base a estrutura etária e a razão de sexo da população, segundo o Censo Demográfico 2000, e aplicando essas mesmas taxas para a estimativa da população de 2015 do IBGE e do Tribunal de Contas da União (TCU). 
oferecido à população de $\mathrm{B}$. $\mathrm{O}$ excesso de oferta total em $\mathrm{A}$, após atender à população de $\mathrm{B}$ e C seria $E_{A+B+C}=-5.000$. Desse modo, para o caso analisado, conclui-se que a localidade $\mathrm{C}$, ainda que se encontre dentro do alcance de $\mathrm{A}$, ou seja, dentro da distância máxima de $60 \mathrm{~km}$ estabelecida para atendimento, é apenas parcialmente coberta pela oferta de serviços de A. No resultado final, o excesso de oferta de A seria exaurido: o município B teria cobertura de $100 \%$ de sua necessidade de exames, já a população de $\mathrm{C}$ terminaria com excesso de demanda de 5.000 .

Já a localidade D encontra-se a mais de $60 \mathrm{~km}$ de distância de A, logo, fora do alcance do centro A, de modo que, embora haja excesso de oferta restante em A, ele não pode ser utilizado para atender à população de D. Esse exemplo ilustra o seguinte cenário: possibilidade de cobertura total pela unidade de serviço de saúde mais próxima; possibilidade de atendimento parcial, restringido pela capacidade de oferta da unidade de saúde; e, por fim, possibilidade de não cobertura, por exceder-se o alcance de atendimento.

Caso algum dos vizinhos de determinado centro regional de oferta de serviços de saúde também apresente excesso de oferta, configura-se uma rede regional de oferta. Em tais casos, a demanda é alocada para a unidade de saúde mais próxima, de acordo com sua capacidade de atendimento.

A distância entre os municípios brasileiros é calculada de acordo com as coordenadas geográficas dos distritos principais pelo método great circle distance. Devido à reduzida escala espacial da unidade de análise, é-se assumida a inexistência de custos de transportes dentro do município de referência, isto é, não se considera a distância interna. Assim, se $d_{i j}$ é a distância entre as localidades $i$ e $j, d_{i j}=0$ se $i=j$. Na prática, o pressuposto de ausência de distância interna equivale à ideia de que toda a população e os equipamentos de saúde em determinado município se encontram no mesmo ponto do espaço - ponto este representado pelas coordenadas geográficas do distrito principal. Uma vez que a população e os equipamentos de um mesmo município estão no mesmo ponto, a distância entre eles é nula, isto é, não existe distância se o deslocamento se restringe a apenas um município. Todavia, se o deslocamento é intermunicipal, considera-se a menor distância geográfica entre as coordenadas dos distritos principais dessas localidades.

\section{RESULTADOS}

Como dito, o objetivo deste estudo é avaliar a provisão espacial de mamógrafos no Brasil a partir de dois aspectos fundamentais: distribuiçẫo espacial de equipamentos e distância entre oferta e demanda deles no âmbito municipal. Se se ignora a fricção espacial e assume-se a inexistência de qualquer limite de distância geográfica entre população e equipamentos para atendimento de saúde, vê-se que os 4.647 mamógrafos em uso no Brasil seriam suficientes para realizar 31,4 milhóes de exames por ano. Por sua vez, os 2.083 mamógrafos disponíveis para o SUS seriam suficientes para realizar 14,08 milhóes de exames anuais. Como a demanda estimada, dada a estrutura etária das mulheres brasileiras, totalizava 12,7 milhóes de exames em 2015, a quantidade de mamógrafos no país representa um excesso de oferta de 147,9\%, quando avaliados todos os equipamentos em uso, e um excesso de oferta de $11,1 \%$, quando são avaliados apenas os que são disponíveis para o SUS. 
Entretanto, a distribuição espacial desses equipamentos não é balanceada ao longo do território nacional. Enquanto algumas regióes concentram parte importante da oferta, outras se encontram distantes de qualquer centro de provisão de serviços de mamografia. O Gráfico 1 compara o equilíbrio entre oferta e demanda por mamografias no Brasil em quatro situaçóes distintas: ignorando a distribuição espacial do equipamento para o total em uso e para os que são disponíveis apenas para o SUS; limitando a análise ao alcance máximo de acesso de $60 \mathrm{~km}$, novamente com a diferenciação entre o total de equipamentos em uso e aqueles que são disponíveis para o SUS.

Gráfico 1: Excesso de demanda e oferta de mamografia (em \% da demanda estimada) no Brasil, de acordo com o alcance máximo

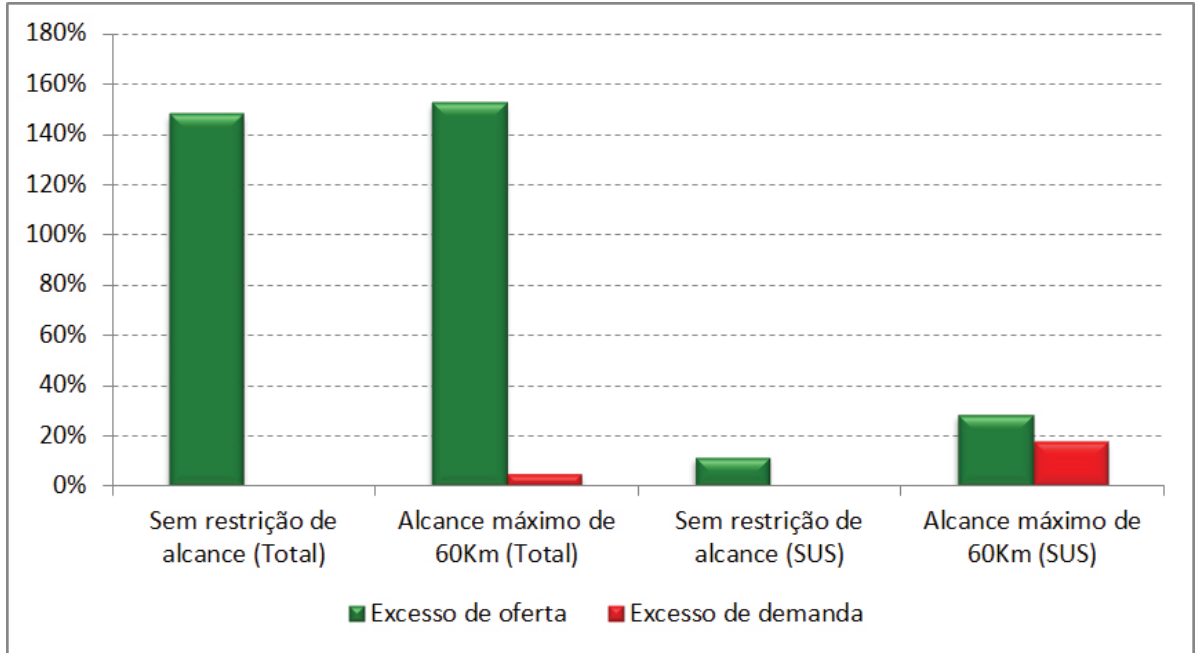

Fonte: Elaborado pelos autores.

Quando se determina que apenas mamógrafos num raio de $60 \mathrm{~km}$ de distância da população podem ser utilizados para atendimento, é possível perceber que o excesso de demanda por mamografias atinge $4,5 \%$ da quantidade de exames demandada. Ou seja, mais de 572 mil exames não seriam realizados por não haver mamógrafos disponíveis num raio de $60 \mathrm{~km}$ de distância da residência da paciente.

Por outro lado, quando são investigados apenas os equipamentos disponíveis para o SUS, o desequilíbrio espacial entre oferta e demanda intensifica-se. Como mencionado, a quantidade de mamógrafos disponíveis para o SUS no Brasil é suficiente para realizar todos os exames necessários, de modo que há um excesso de oferta correspondente a $11,1 \%$ do total de exames esperados. Todavia, quando se estipula uma distância máxima de $60 \mathrm{~km}$ entre o município de residência da paciente e o município onde se encontra a unidade de saúde com mamógrafo disponível, há um forte desequilíbrio entre oferta e demanda. Com essa delimitação, 17,2\% dos exames esperados não são realizados por falta de mamógrafos; em contraste, regióes em que há concentração da oferta do equipamento apresentam um excesso de oferta de 28,3\%. Ou seja, a alocação de mamógrafos disponíveis para o SUS é concentrada espacialmente: enquanto em algumas regiōes brasileiras há excesso de oferta, em outras, os equipamentos são insuficientes. Como consequência dessa concentração, verifica-se uma situação que aparenta um equilíbrio bastante satisfatório quando não se leva em conta a distância entre paciente e equipamento, algo que esconde, na 
verdade, um relevante desequilíbrio. Ao se limitar a distância entre paciente e mamógrafo a no máximo $60 \mathrm{~km}$, mais de 2,1 milhôes de exames não podem ser realizados por falta de equipamento disponível - quase 1 para cada 5,8 exames esperados.

Ao analisar a oferta de mamógrafos disponíveis para o SUS no âmbito estadual (Figura 4), observa-se que todas as regióes brasileiras apresentam Estados em que há maior quantidade de mamógrafos do que o esperado. A única exceção é a região Sul, em cujos Estados a quantidade de mamógrafos é suficiente para atender toda a população, apesar de apresentar ineficiência na alocação de mamógrafos.

Cabe ressaltar a situação do Paraná, da Bahia e do Mato grosso do Sul. Nesses Estados, a quantidade de mamógrafos disponível para o SUS é suficiente para atender toda a demanda esperada, e haveria pouca subutilização, caso não fosse estabelecida uma distância máxima entre paciente e equipamento. Entretanto, ao se restringir essa distância a $60 \mathrm{~km}$, a ineficiência da alocação de equipamentos é bastante considerável - 16\% (Paraná), 13\% (Bahia) e 33\% (Mato Grosso do Sul) da demanda esperada por mamografias não pode ser atendida por falta de equipamento.

Figura 4: Excessos de demanda e oferta de mamografia (em \% da demanda estimada) com alcance máximo de $60 \mathrm{~km}$, considerando mamógrafos disponíveis para o SUS

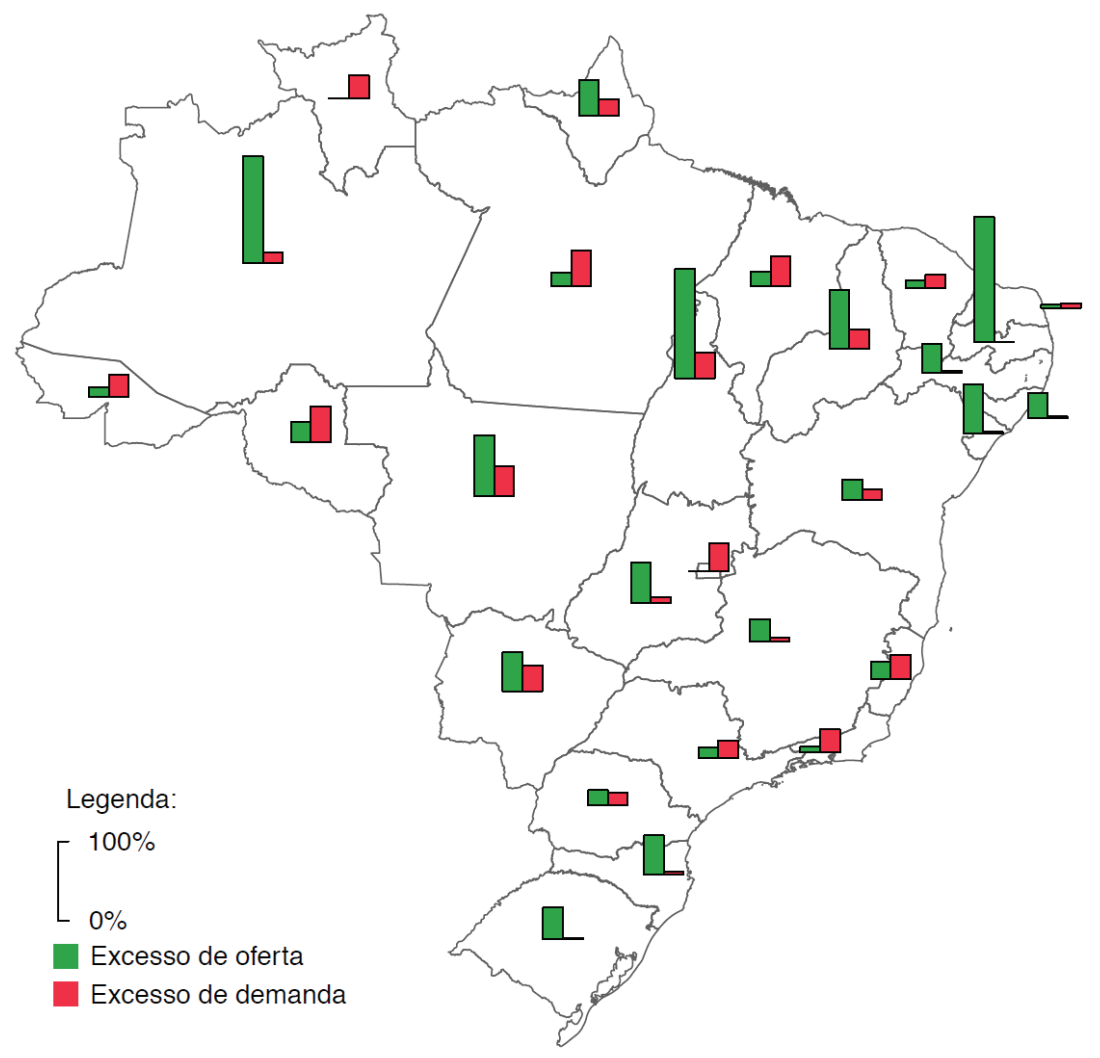

Fonte: Elaborado pelos autores.

No Espírito Santo, a situação é diferente, mas também aí há evidência de má alocação. Vê-se um excesso de demanda por mamografias de $9 \%$, ou seja, a quantidade de mamógrafos disponíveis para o SUS encontra-se abaixo do esperado. Quando se limita a distância a $60 \mathrm{~km}$, esse número salta para $31 \%$. 
A Figura 5 ilustra a distribuição dos municípios brasileiros segundo percentual da demanda esperada por exames, coberta por provisão de mamógrafos disponíveis para o SUS de acordo com a distância máxima de $60 \mathrm{~km}$ e a capacidade dos equipamentos. Cada círculo representa um município e encontra-se nas coordenadas do distrito principal de cada município. Os círculos em verde escuro indicam municípios que operam como centros regionais de oferta de mamógrafos e possuem excesso de oferta do equipamento. Os círculos em verde claro ilustram municípios cuja demanda esperada por mamografias encontra-se $100 \%$ coberta por alguma unidade de saúde com oferta de mamógrafo num raio de $60 \mathrm{~km}$, podendo esse centro ser o próprio município. Os círculos amarelos indicam municípios em que apenas uma parte da demanda por mamografias encontra-se coberta; os círculos vermelhos representam municípios em que toda a população encontra-se a mais de $60 \mathrm{~km}$ de qualquer unidade de saúde com mamógrafos disponíveis.

Do total de 5.565 municípios brasileiros, 1.160 (20,8\%) apresentam menos de $100 \%$ de sua demanda esperada por mamografias coberta por unidade de saúde com mamógrafo disponível para o SUS num raio de $60 \mathrm{~km}$. Esses municípios concentramse principalmente no Maranhão (118 municípios), Bahia (114 municípios) e Piauí (105 municípios). Cabe assinalar que no Estado do Mato Grosso o número de municípios com cobertura inferior a $100 \%$ da população representa $73,8 \%$ do total.

Figura 5: Porcentagem da demanda por mamografia coberta por potencial oferta de mamógrafo disponível pelo SUS, considerando o alcance máximo de $60 \mathrm{~km}$

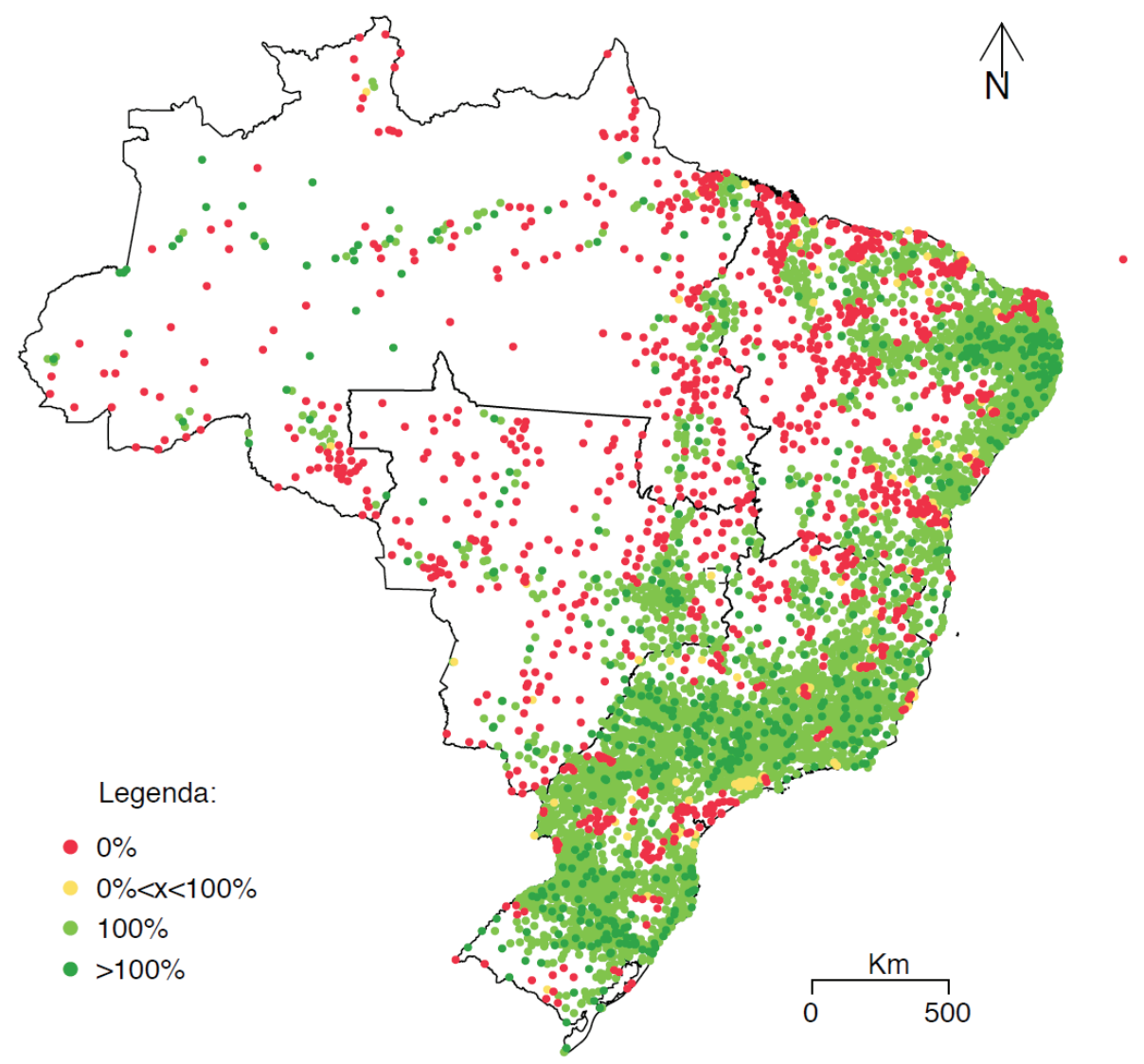

Fonte: Elaborado pelos autores. 
Como é possível perceber, na Figura 5, as regióes Norte e Centro-Oeste possuem a maior proporção de municípios cuja demanda por mamografia não pode ser atendida num raio de $60 \mathrm{~km}$. No Nordeste, próximo ao litoral, há uma concentração de municípios com excesso de oferta, enquanto o interior da regiáo concentra a maior quantidade de municípios sem cobertura total. Destaque-se, ainda, a elevada proporção de municípios sem cobertura total no Paraná e em Minas Gerais. No primeiro, 16\% dos municípios não possuem cobertura total; no segundo, esse número é de 11,7\%.

Pedro Amaral é graduado e mestre em Economia pela Universidade Federal de Minas Gerais (UFMG); doutor em Economia pela University of Cambridge, Inglaterra; professor adjunto no Centro de Desenvolvimento e Planejamento Regional (CEDEPLAR) da UFMG.

E-mail:pedrovma@cedeplar. ufmg.br

Luciana Luz é graduada em Economia e mestra em Demografia pela Universidade Federal de Minas Gerais (UFMG); doutora em Sociologia pela Arizona State University, Estados Unidos; professora adjunta no Centro de Desenvolvimento e Planejamento Regional (CEDEPLAR) da UFMG.

E-mail: lucianaluz@cedeplar. ufmg.br

Francisco Cardoso é graduado em Medicina pela Faculdade de Ciências Médicas de Minas Gerais; mestre em Administração pela Universidade Federal de Minas Gerais (UFMG); pesquisador do Núcleo de Educação em Saúde Coletiva (NESCON) da UFMG.

E-mail: cardoso@nescon. medicina.ufmg.br

Rosiene Freitas é graduada em Ciências Biológicas, mestra em Saúde Pública e doutora em Ciência Política pela Universidade Federal de Minas Gerais (UFMG); pesquisadora do Núcleo de Educação em Saúde Coletiva (NESCON) da UFMG.

E-mail: rosiene.freitas@ hotmail.com

Artigo recebido em 18 de julho de 2016 e aprovado para publicação em 24 de novembro de 2016.

\section{CONSIDERAÇÕES FINAIS}

O foco deste trabalho é avaliar a rede de oferta de mamógrafos no Brasil, a partir de dois aspectos principais para uma oferta espacialmente equilibrada de serviços: disponibilidade regional do equipamento e distância entre demanda e oferta de mamógrafos no âmbito municipal. Os resultados encontrados demonstram que a quantidade total de mamógrafos em uso no Brasil e também daqueles disponíveis para o SUS é suficiente para o atendimento total da população, segundo os parâmetros propostos para disponibilização desses equipamentos pelo Ministério da Saúde (BRASIL, 2015). Todavia, quando se limita o alcance da oferta a uma distância máxima de $60 \mathrm{~km}$, é possível identificar regiōes no país em que parte da população permanece sem cobertura pela provisão do equipamento; outras regiôes, em contrapartida, concentram quantidade de equipamento superior à que seria necessária, indicando uma ineficiência locacional na distribuição espacial dos mamógrafos.

Vale ressaltar que a análise deste artigo foi construída à luz do conceito de provisão espacialmente equilibrada de equipamentos de saúde - oferta e demanda foram avaliadas de acordo com a quantidade de equipamentos disponíveis (total ou para o SUS) nas unidades de saúde e a demanda por mamografias nos municípios brasileiros. Nesse sentido, o único fator que exerce influência para que a demanda seja atendida pela oferta é a distância. Porém, vários outros fatores podem afetar o acesso aos equipamentos. Algumas regiôes, apesar de favorecidas por uma rede adequada de oferta de mamógrafos, podem apresentar acessibilidade limitada devido à falta de conhecimento dessa disponibilidade, aos custos de transporte, à infraestrutura, às barreiras culturais, entre outros fatores. Em outras palavras, a disponibilidade de equipamentos não garante acessibilidade. Entretanto, sem a disponibilidade do equipamento, não há sentido falar de acessibilidade.

Os resultados demonstram que a oferta de mamógrafos no Brasil pode ser aprimorada por meio de uma avaliação das demandas locacionais. O nível de detalhamento da análise aqui empreendida permite verificar que a distribuição de mamógrafos disponíveis pelo SUS é ineficiente em vários Estados. Dada a permanente restrição orçamentária para investimentos em equipamentos de saúde no Brasil restrição que não é exclusiva da área de saúde -, é necessário um melhor planejamento da alocação desses equipamentos, evitando critérios que, por ventura, venham a ser clientelistas ou ligados a questôes de caráter político. Em outros termos, é preciso planejar a alocação de investimentos tendo como meta a melhoria do bem-estar da populaçãa e a redução das desigualdades. A alocação de equipamentos em municípios e regiôes menos densas, desde que tomando como base as demandas e especificidades locais, aparece como uma importante ferramenta para reduzir as disparidades 
regionais. Uma vez que as açôes do SUS fundamentam-se no conceito de garantia de acesso igualitário à saúde a todos os cidadãos, a busca pela provisão de equipamentos de saúde espacialmente equilibrada deve ser tomada como uma parte importante de sua agenda.

\section{REFERÊNCIAS}

ADAY, L. A.; ANDERSEN, R. A framework for the study of access to medical care. Health Services Research, v. 9, n. 3, p. 208-220, 1974. Disponível em: <https://www.ncbi.nlm. nih.gov/pmc/articles/PMC1071804/>. Acesso em: 20 jan. 2017.

ANDRADE, E.; CAMPOS, F.; FREITAS, R. Projeto de Revisão dos Parâmetros de Programação das Açôes de Atenção à Saúde: parâmetros de necessidade de mamógrafos. 2013. Mimeo.

ANDREWS, G. J.; MOON, G. Space, place, and the evidence base: part I - an introduction to health geography. Worldviews on Evidence-Based Nursing, v. 2, n. 2, p. 55-62, jun. 2005. https://doi.org/10.1111/j.1741-6787.2005.05004.x

BOTEGA, L. A.; RODRIGUES, R. N.; ANDRADE, M. V. Distribuiçâo espacial das internaçōes hospitalares realizadas pelo Sistema Único de Saúde (SUS) em Minas Gerais, 2002: utilização dos serviços de saúde e distância média percorrida pelos pacientes. In: ENCONTRO NACIONAL DE ESTUDOS POPULACIONAIS, 15., 2006, Caxambu. Anais... Caxambu: ABEP, 2006. Disponível em: <http://www.abep.org.br/ publicacoes/index.php/anais/article/view/1565/0>. Acesso em: 20 jan. 2017.

BRASIL. Ministério da Saúde. Portaria no 1.101, de 12 de junho de 2002. Estabelece os parâmetros de cobertura assistencial no âmbito do Sistema Único de Saúde - SUS. Diário Oficial da República Federativa do Brasil, Brasília, 13 jun. 2002.

. Ministério da Saúde. Critérios e parâmetros para o planejamento e programação de açôes e serviços de saúde no âmbito do sistema único de saúde: parâmetros SUS. Brasília: Ministério da Saúde, 2015.

BROWN, T.; DUNCAN, C. Placing geographies of public health. Area, v. 34, n. 4, p. 361-369, dez. 2002. https://doi.org/10.1111/1475-4762.00093

DONABEDIAN, A. Aspects of medical care administration. Cambridge: Harvard University Press, 1973.

GASPARINI, C. E.; RAMOS, F. S. Relative deficit of health services in Brazilian states and regions. Brazilian Review of Econometrics, v. 24, n. 1, p. 75-107, maio 2004. Disponível em: <http://bibliotecadigital.fgv.br/ojs/index.php/bre/article/view/2704>. Acesso em: 20 jan. 2017.

HAMER, L. Improving patient access to health services: a national review and case studies of current approaches. London: Health Development Agency, 2004.

HART, J. T. The inverse care law. The Lancet, v. 297, n. 7696, p. 405-412, fev. 1971. https:// doi.org/10.1016/S0140-6736(71)92410-X

HIGGS, G. A literature review of the use of GIS-based measures of access to health care services. Health Services and Outcomes Research Methodology, v. 5, n. 2, p. 119-139, jun. 2004. https://doi.org/10.1007/s10742-005-4304-7

. The role of GIS for health utilization studies: literature review. Health Services and Outcomes Research Methodology, v. 9, n. 2, p. 84-99, jun. 2009. https://doi.org/10.1007/ s10742-009-0046-2

INSTITUTO NACIONAL DE CÂNCER (INCA). Parâmetros para o rastreamento do câncer de mama: recomendaçóes para gestores estaduais e municipais. Ministério da 
saúde, Instituto Nacional de Câncer. Rio de Janeiro: INCA, 2009.

- Nota técnica: Parâmetro para cálculo da capacidade de produção do mamógrafo simples, 23 fev. 2012. Disponível em: <http:/www2.inca.gov.br/wps/wcm/connect/ a79eb3804eb684918aa79af11fae00ee/Par\%C3\%A2metro+de+produ\%C3\%A7\%C3\%A3o+do+mam\%C3\%B3grafo+simples.pdf?MOD=AJPERES\&CACHEI-

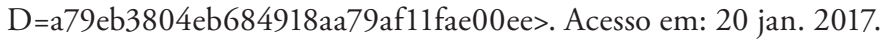

IUNES, R. A concepção econômica de custos. In: PIOLA, S. F.; VIANNA, S. M. (Org.). Economia da saúde: conceito e contribuição para a gestão da saúde. Brasília: IPEA, 1995. p. 227-247.

JOSEPH, A.; BANTOCK, P. Measuring potential physical accessibility to general practitioners in rural areas: a method and case study. Social Science and Medicine, v. 16, n. 1, p. 85-90, jan. 1982. https://doi.org/10.1016/0277-9536(82)90428-2

KEARNS, R.; MOON, G. From medical to health geography: novelty, place and theory after a decade of change. Progress in Human Geography, v. 26, n. 5, p. 605-625, out. 2002. https://doi.org/10.1191/0309132502ph389oa

KHAN, A. A. An integrated approach to measuring potential spatial access to health care services. Socio-Economic Planning Sciences, v. 26, n. 4, p. 275-287, out. 1992. https:// doi.org/10.1016/0038-0121(92)90004-o

KUHN, M.; OCHSEN, C. Demographic and geographic determinants of regional physician supply. Thünen-series of applied economic theory, n. 105, p. 1-48, 2009. Disponível em: <https://www.econstor.eu/bitstream/10419/39775/1/610728547.pdf>. Acesso em: 20 jan. 2017.

MAYER, J. D. Relations between two traditions of medical geography: health systems planning and geographical epidemiology. Progress in Human Geography, v. 6, n. 2, p. 216-230, jun. 1982.

NORONHA, K. Dois ensaios sobre desigualdade social em saúde. 2001. Dissertação (Mestrado em Economia) - Centro de Desenvolvimento e Planejamento Regional, Universidade Federal de Minas Gerais, Belo Horizonte, 2001.

OLIVEIRA, A. C.; SIMÓES, R. F.; ANDRADE, M. V. Regionalização dos serviços de média e alta complexidade hospitalar e ambulatorial em Minas Gerais: estrutura corrente versus estrutura planejada. In: SEMINÁRIO SOBRE A ECONOMIA MINEIRA, 13., 2008, Diamantina. Anais... Belo Horizonte: Cedeplar/UFMG, 2008.

OLIVEIRA, E. X. G. Fluxo de internaçôes hospitalares em Minas Gerais: estudos de políticas de saúde e de avaliação econômica do SUS MG. Belo Horizonte: Fundação João Pinheiro, 2004.

; CARVAlHO, M. S.; TRAVASSOS, C. Territórios do Sistema Único de Saúde: mapeamento das redes de atenção hospitalar. Cadernos de Saúde Pública, v. 20, n. 2, p. 386-402, mar./abr. 2004. https://doi.org/10.1590/S0102-311X2004000200006

; TRAVASSOS, C.; CARVALHO, M. S. Acesso à internação hospitalar nos municípios brasileiros em 2000: territórios do Sistema Único de Saúde. Cadernos de Saúde Pública, v. 20, sup. 2, p. 298-309, 2004. https://doi.org/10.1590/S0102$311 \mathrm{X} 2004000800023$

POL, L.; THOMAS, R. The demography of health and health care. 2. ed. Nova Iorque: Plenum, 2000.

PÓVOA, L.; ANDRADE, M.; MORO, S. Distribuição dos empregos médicos em Minas Gerais: uma análise à luz da economia espacial. In: SEMINÁRIO SOBRE A ECONOMIA MINEIRA, 11., 2004, Diamantina. Anais... Belo Horizonte: Cedeplar/ UFMG, 2004.

RODRIGUES, C. G.; AMARAL, P. V. M.; SIMÓES, R. F. Rede urbana na oferta de serviços de saúde: uma análise multivariada macro regional - Brasil, 2002. Revista de 
Desenvolvimento Econômico, v. 9, n. 15, p. 83-92, dez. 2007. Disponível em: <http:// www.revistas.unifacs.br/index.php/rde/article/view/1018>. Acesso em: 20 jan. 2017.

SIMÓES, R. F.; RODRIGUES, C. G.; AMARAL, P. V. Distribuição da rede de oferta de serviços de saúde na região Norte: uma análise espacial multivariada. In: RIVERO, S.; JAYME JR., F. G. (Org.). As Amazônias do Século XXI. Belém: Ed. UFPA, 2008. p. 261-291.

SIMÓES, R. F. et al. Disparidades regionais mineiras na oferta de serviços de saúde. In: FONTES, R.; FONTES, M. (Org.). Crescimento e desigualdade regional em Minas Gerais. Viçosa: Folha de Viçosa, 2005. p. 293-324.

SUI, D. Z. Geographic Information Systems and medical geography: toward a new synergy. Geography Compass, v. 1, n. 3, p. 556-582, maio 2007. https://doi.org/10.1111/j. 1749-8198.2007.00027.x

VILLAR, V. C. F. L. et al. Distribuição dos mamógrafos e dos exames mamográficos no estado do Rio de Janeiro, 2012 e 2013. Epidemiologia e Serviços de Saúde, v. 24, n. 1, p. 105-114, mar. 2015. https://doi.org/10.5123/S1679-49742015000100012

WHITEHEAD, M. The concepts and principles of equity and health. International Journal of Health Services, v. 22, n. 3, p. 429-445, jul. 1992. https://doi.org/10.2190/9861-lhq62vte-yrrn 